\title{
SISTEM INFORMASI KEGIATAN PENUNJANG AKADEMIK MAHASISWA BERBASIS DESKTOP
}

\author{
Dewi Sahara Naution ${ }^{1}$, Faiz Rafdhi ${ }^{2}$ \\ ${ }^{1,2}$ STMIK Muhammadiyah Jakarta \\ 11dewistmikmj@gmail.com, ${ }^{2}$ faizrafdhi@gmail.com
}

\begin{abstract}
ABSTRAK
Seiring dengan perkembangan ilmu pengetahuan dan teknologi saat ini, peranan dan pemanfaatan teknologi informasi menjadi penting, dalam penyusunan jadwal kegiatan penunjang akademik di STMIK MJ yang dilaksanakan setiap tahun mengalami beberapa permasalahan yaitu terkait dengan data kegiatan yang dilaksanakan masih belum terdata dengan baik dan daftar nama mahasiwa yang telah mengikuti kegiatan-kegiatan yang telah dilaksanakan,sehingga proses pembuatan sertifikat dan jadwal kegiatan tersebut tidak efektif dan efisien. Dalam membangun Sistem Informasi Kegiatan Penunjang Akademik Mahasiswa pada STMIK Muhammadiyah Jakarta menggunakan VB.Net sebagai bahasa programnya dan MySQL sebagai databasenya. Pengembangan sistem ini menggunakan model waterfall dengan tahapan analisis, desain, kode, dan tes. Penelitian ini menghasilkan Sistem Informasi Penunjang Kegiatan Akademik Mahasiswa yang dapat memudahkan proses input data kegiatan mahasiswa dapat dilakukan dengan cepat, akurat dan efisien. Sistem yang dibangun dapat menampilkan data mahasiswa secara keseluruhan, yaitu berupa daftar kegiatan, data waktu pelaksanaan kegiatan, serta kegiatan yang telah diikuti.
\end{abstract}

Kata Kunci: Sistem Informasi; Kegiatan Penunjang Akademik; MySQL; model waterfall

\section{PENDAHULUAN}

Berdasarkan observasi yang dilakukan di kampus Sekolah Tinggi Manajemen Informatika dan Komputer Muhammadiyah Jakarta (STMIK MJ) dalam penginputan data kegiatan penunjang akademuk yang dilakukan sudah menggunakan alat bantu komputer tetapi belum digunakan secara optimal, masih menggunakan program aplikasi Microsoft Excel dengan menggunakan logika/ formula yang disediakan program tersebut. Kendala yang sering dihadapi panitia kegiatan dan staff akademik dalam pengolahan dan pembuatan penjadwalan kegiatan antara lain lambatnya proses pembuatan jadwal kegiatan, daftar mahasiswa yang telah melaksanakan kegiatan, lambat dalam pembuatan laporan dan juga aplikasi tersebut belum memiliki sistem database tersendiri.

Berdasarkan uraian di atas maka penulis akan merancang Sistem Informasi Kegiatan Penunjang akademik secara komputerisasi dirancang dengan menggunakan VB.Net dan MySQL. Sistem yang dirancang berfungsi untuk membantu staff akademik dan panitia pelaksana kegiatan dalam pengolahan data mahasiswa dan pembuatan jadwal pelaksanaan kegiatan di Kampus STMIK Muhammadiyah Jakarta.

\subsection{Identifikasi Masalah}

Memiliki latar belakang yang telah disebutkan masalah dapat di identfikasi sebagai berikut:

1. Tidak ada data yang jelas mengenai daftar mahasiswa yang telah menyelesaikan kegiatan yang dilaksanakan. Dari kegiatan yang telah dilakukan persentase data setiap kegiatan yang dimiliki yaitu :

- OPT: Tahun 2015-2020 =60\%

- Baitul Arqam: Tahun 2015-2020 =65\%

- Visualisasi Basic Islam: Tahun 2015$2020=60 \%$

- Tilawah Ibadah Khitabah: Tahun 2019$2020=85 \%$

- Seminar Informasi Dakwah: Tahun 2015-2020 = 70\%

- Seminar Proposal Skripsi: 2015-2020 = $75 \%$

- Kuliah Kerja Praktek: 2015-2020= $75 \%$

- Skripsi: Tahun 2015-2020 = 80\%

2. Tidak ada penjadwalan yang jelas mengenai kegiatan-kegiatan penunjang akademik yang telah dilaksanakan 
3. Pembagian sertifikat yang tidak terverifikasi.

\subsection{Batasan Masalah}

Pada penulisan artikel ini penulis membatasi permasalahan sebagai berikut:

1. Pengguna sistem terbagi menjadi 3 yaitu admin (Panitia), Ketua Program Studi (KPS), Waket Bidang Akademik \& Kemahasiswaan dan Ka.BAAK

2. Sistem Informasi ini hanya meliputi data mahasiswa, daftar kegiatan, data waktu pelaksanaan kegiatan, kegiatan yang telah diikuti.

3. Sistem informasi ni hanya meliputi kegiatan penunjang akademik yang wajib mahasiswa ikuti selama perkuliahan yaitu Orientasi mahasiwa baru, Baitul Arqam (BA), Visualisasi Basic Islam (ViBI), Ujian Tilawah Ibadah Kitabah (TIK) pada STMIK Muhammadiyah Jakarta.

4. Aplikasi ditambahkan kegiatan akademik yaitu Sistem Informasi Dakwah (SID), Seminar Proposal Skripsi (SPS), Kuliah Kerja Praktek (KKP), dan Sidang Skripsi

5. Pembuatan sistem informasi data kegiatan menggunakan VB.Net sebagai bahasa programnya dan $M y S Q L$ sebagai database.

6. Sistem yang dijalankan menggunakan Software Xampp sebagai localhost dan belum dapat diakses melalui internet, berbasis desktop.

\subsection{Rumusan Masalah}

Berdasarkan identifikasi masalah di atas, penulis membuat rumusan masalah sebagai berikut:

1. Bagaimana membuat sistem infomasi yang dapat menyelesaikan masalah yang tertera pada identifikasi masalah di atas?

2. Bagaimana mengimplementasikan sistem informasi kegiatan penunjang akademik pada STMIK Muhammadiyah Jakarta?

\section{TINJAUAN PUSTAKA}

\subsection{Sistem}

Sistem adalah kumpulan jaringan yang saling bekerjasama dengan ketentuan aturan yang sistematis dan terstruktur untuk membentuk satu kesatuan yang melaksanakan suatu fungsi untuk mencapai tujuan[1].

\subsection{Informasi}

Informasi adalah data yang telah diolah menjadi berguna dan memiliki arti bagi penerimanya, serta mengurangi ketidakpastian saat proses pengambilan keputusan mengenai suatu keadaan. Informasi adalah hasil pemrosesan data (fakta) menjadi sesuatu yang bermakna dan bernilai untuk pengambilan keputusan[2].

\subsection{Sistem Informasi}

Sistem Informasi adalah suatu sistem di dalam suatu organisasi yang mempertemukan kebutuhan pengelolaan transaksi harian, mendukung operasi, bersifat manajerial, dan kegiatan strategi dari suatu organisasi dan menyediakan pihak luar tertentu dengan laporan-laporan yang di butuhkan[3].

\subsection{Kegiatan Penunjang Akademik Mahasiswa}

Kegiatan penunjang akademik adalah salah satu kegiatan yang dapat menunjang soft skill mahasiswa dan dapat menjadi syarat dalam memenuhi Satuan Kredit Partisipasi (SKP) untuk salah satu syarat kelulusan[4].

\subsection{Desktop Based}

Desktop based adalah aplikasi berbasis desktop yang berjalan di satu atau beberapa komputer (terhubung dalam satu jaringan) secara independen dan tidak memerlukan browser. Untuk membuat sistem desktop based beberapa hal yang sangat penting untuk membangun sebuah sistem, diantaranya:

1. Hardware yang akan digunakan nantinya ketika sistem tersebut sudah menjadi program yang utuh haruslah sesuai dengan kebutuhan dan dengan spesifikasi yang lebih tangguh lagi.

2. Server yang akan digunakan untuk penyimpanan data dari klien saat mengirimkan data penting harus dengan spesifikasi yang kuat agar tidak terjadi error/hang saat diakses.

3. Memiliki infrastruktur jaringan yang tidak terlalu besar karena aplikasi hanya diakses dijaringan dalam (intranet) saja sudah cukup.

4. Tidak dapat diakses dari jaringan luar (internet) jika ingin menunjukkan laporan yang telah diinput dan dihasilkan oleh sistem/aplikasi tersebut.

5. Jika aplikasi yang sudah diinstall di PC maupun server, sangat susah untuk melakukan update pada sistemnya jika 
masih ada kekurangan dalam pengaksesannya dan membutuhkan waktu yang cukup lama [5]

\section{METODOLOGI PENELITIAN}

\subsection{Metode Pengumpulan Data}

1. Observasi

Peneliti mengunjungi langsung kampus STMIK Muhammadiyah Jakarta untuk melihat proses kegiatan dan mengetahui permasalahan yang terjadi. Pada waktu melakukan observasi, peneliti juga melakukan beberapa wawancara singkat terhadap bagian kemahasiswaan. Observasi yang dilakukan untuk mengetahui kebutuhan pengguna pada sistem yang dibuat. Observasi juga digunakan untuk mengumpulkan data yang diperlukan dalam pembuatan sistem.

\section{Studi Pustaka}

Kegiatan Studi Pustaka dilakukan untuk mencari teori pendukung dalam pembuatan penelitian. Peneliti membaca serta mempelajari dari buku referensi, browsing di internet, dan perpustakaan kampus STMIK Muhammadiyah Jakarta.

\subsection{Metodologi Pengembangan Sistem}

Metode pengembangan sistem yang penulis gunakan adalah metode System Development Life Cycle (SDLC). Model Waterfall merupakan salah satu metode dalam SDLC yang akan digunakan untuk mengembangkan perangkat lunak ini. Model waterfall adalah suatu proses perkembangan perangkat lunak secara berurutan, aliran sistem perangkat lunak di pandang terus

Tabel 1. Kebutuhan Hardware

\begin{tabular}{|c|c|c|}
\hline No & Nama Hardware & Spesifikasi \\
\hline 1 & Processor & $\begin{array}{c}\text { Intel(R) Core (TM) } \\
\text { i3 CPU 550 @ } \\
3.20 \mathrm{GHz}\end{array}$ \\
\hline 2 & RAM & $2.00 \mathrm{~GB}$ \\
\hline 3 & Hardisk & $150 \mathrm{~GB}$ \\
\hline 4 & $\begin{array}{c}\text { Mouse \& } \\
\text { Keyboard }\end{array}$ & Standar \\
\hline 5 & Koneksi Internet & LAN \\
\hline
\end{tabular}

2. Kebutuhan Software

Adapun perangkat lunak (software) yang digunakan dalam pembuatan sistem ini adalah sebagai berikut: mengalir kebawah di ibaratkan seperti air terjun yang melewati fase perencanaan, pemodelan, implementasi dan pengujian.

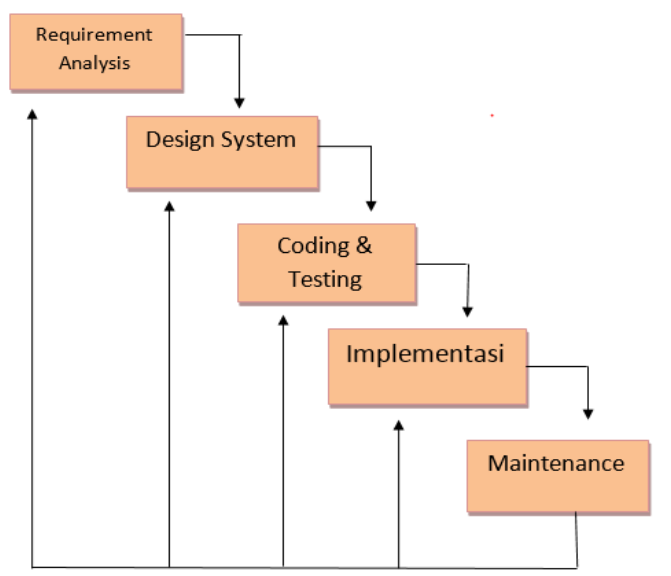

Gambar 1. Pengembangan Metode Waterfall (Pressman)

\section{HASIL DAN PEMBAHASAN}

Pada metodolgi penelitian yang digunakan terdapat beberapa tahap yang dilakukan dalam pengembangan sistem informasi kegiatan penunjang akademik mahasiswa, antara lain Requirement Analysis, Desaign System, Coding \& Testing, Implementasi, Maintenance.

\subsection{Tahap Requirement Analyst System (Analisa kebutuhan sistem)}

1. Kebutuhan Hardware

Dalam menerapkan dari rancangan yang telah di jelaskan sebelumnya di butuhkan beberapa perangkat keras dalam pembuatan sistem ini. Adapun alat-alat yang dibutuhkan adalah:

Tabel 2. Kebutuhan Software

\begin{tabular}{|c|l|c|}
\hline No & Nama Aplikasi & Keterangan \\
\hline 1 & Ms Windows 8 & Sebagai OS \\
\hline 2 & XAMPP & Sebagai Web Server \\
\hline 3 & $\begin{array}{l}\text { Microsoft } \\
\text { Visual Studio } \\
2010\end{array}$ & $\begin{array}{c}\text { Aplikasi dan Desain } \\
\text { Sistem Aplikasi }\end{array}$ \\
\hline 4 & $\begin{array}{l}\text { Microsoft Word } \\
2007\end{array}$ & $\begin{array}{c}\text { Sebagai Pembuatan } \\
\text { Rancang Bangun } \\
\text { Aplikasi }\end{array}$ \\
\hline 5 & Edraw Max & $\begin{array}{c}\text { Sebagai Pembuatan } \\
\text { Diagram UML }\end{array}$ \\
\hline 6 & $\begin{array}{l}\text { Ms. powerpoint } \\
2013\end{array}$ & $\begin{array}{c}\text { Sebagai desain } \\
\text { tampilan aplikasi }\end{array}$ \\
\hline 7 & Google Chrome & Browser database \\
\hline
\end{tabular}




\section{Analisa Kebutuhan Brainware}

Dari penelitian di lapangan dan berdasarkan kebutuhan untuk mengembangkan sistem lama ke sistem baru, Sumber daya manusia yang di butuhkan dalam pembuatan web sistem informasi kegitatan penujang akademik mahasiswa ini antara lain:

a. Admin pihak yang bertugas dalam menjalankan sistem dari input, hapus, batal sampai pencetakan laporan serta mengelola database sistem yang telah di buat, Panitia Kegiatan memiliki hak akses sama seperti admin.

b. User adalah pihak yang menggunakan sistem ini, yaitu Ketua Program Studi Sistem Informasi, Ketua Program Studi Teknik Informatika, Kepala PUSAKA, Waket Bidang Kemahasiswaan dan Akademik, Kepala Bagian Akademik. User hanya bisa mengecek laporan kegiatan yang ada.

4. Analis sistem yang sedang berjalan

Peneliti telah melakukan observasi kinerja sistem yang ada di STMIK Muhammadiyah Jakarta mengenai sistem informasi kegiatan penunjang akademik mahasiswa, peneliti telah menganalisa sistem yang berjalan pada kegiatan di kampus STMIK MJ. Selama ini system pendataan yang ada belum terorganisir dan masih menggunakan aplikasi pengolah angka yaitu Microsoft Office Excel. Untuk mengatasi permasalah tersebut maka diperlukan sistem informasi aplikasi berbasis desktop guna mempercepat pencarian, memudahkan penginputan data kegiatan, pengecekan status kegiatan serta user tracker dalam penginputan data.

\subsection{Tahap Desain Sistem}

Pada tahap perancangan aplikasi menggunakan diagram Unified Modeling Language (UML) sebagai alat bantu. Diagram UML yang digunakan dalam perancangan sistem adalah use casediagram, activity diagram, sewuence diagram, class diagram. Analisa yang dilakukan di kampus STMIK MJ, menghasilkan perancangan sistem informasi kegiatan penunjang akademik mahasiswa, yang akan peneliti Bangun berdasarkan data kegiatan observasi yang telah dilakukan. Menyimpulkan dari hasil observasi yang dilakukan memerlukan alur sebuah sistem yang akan di rancang sebagai berikut.

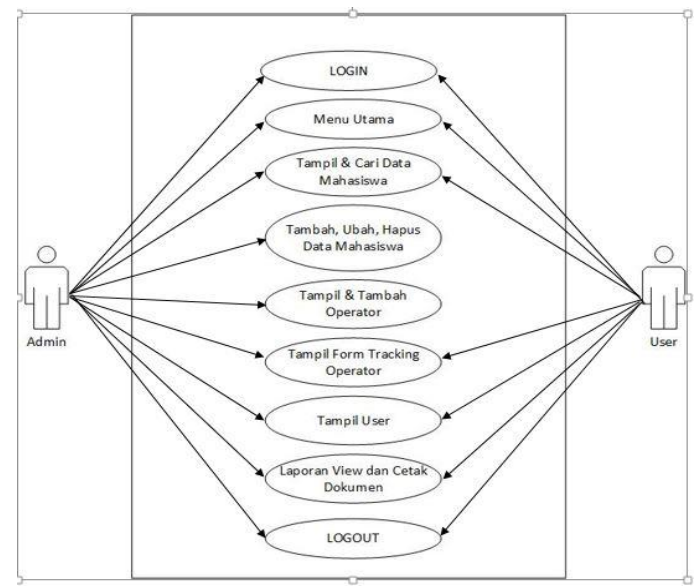

Gambar 2. Use case diagram sistem

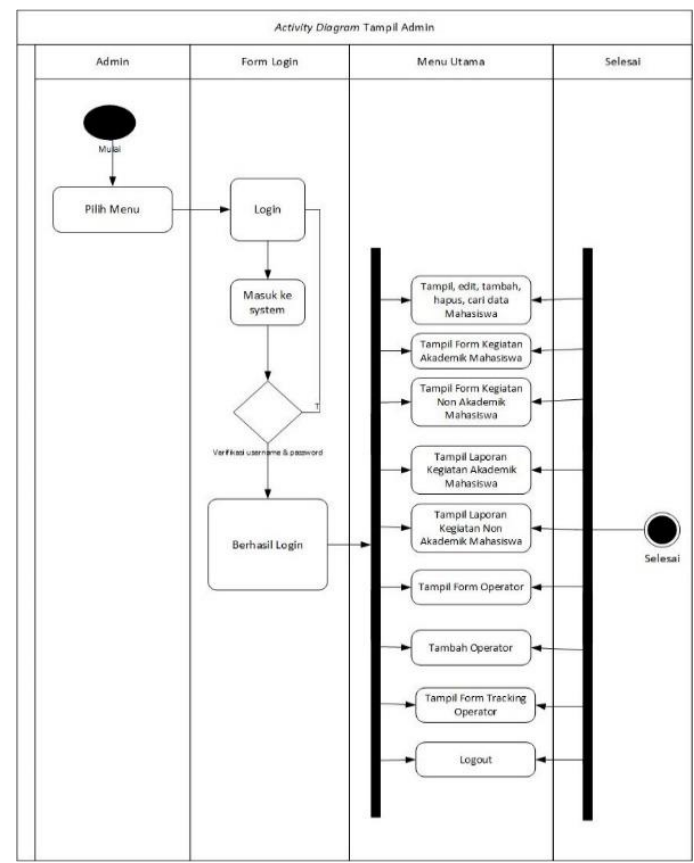

Gambar 3. Activity Diagram Sistem

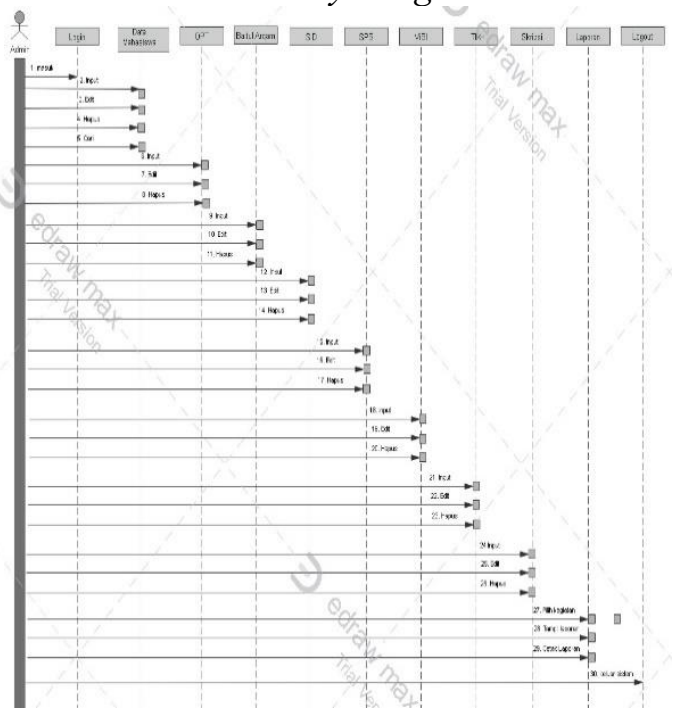

Gambar 4. Sequence Diagram sistem 


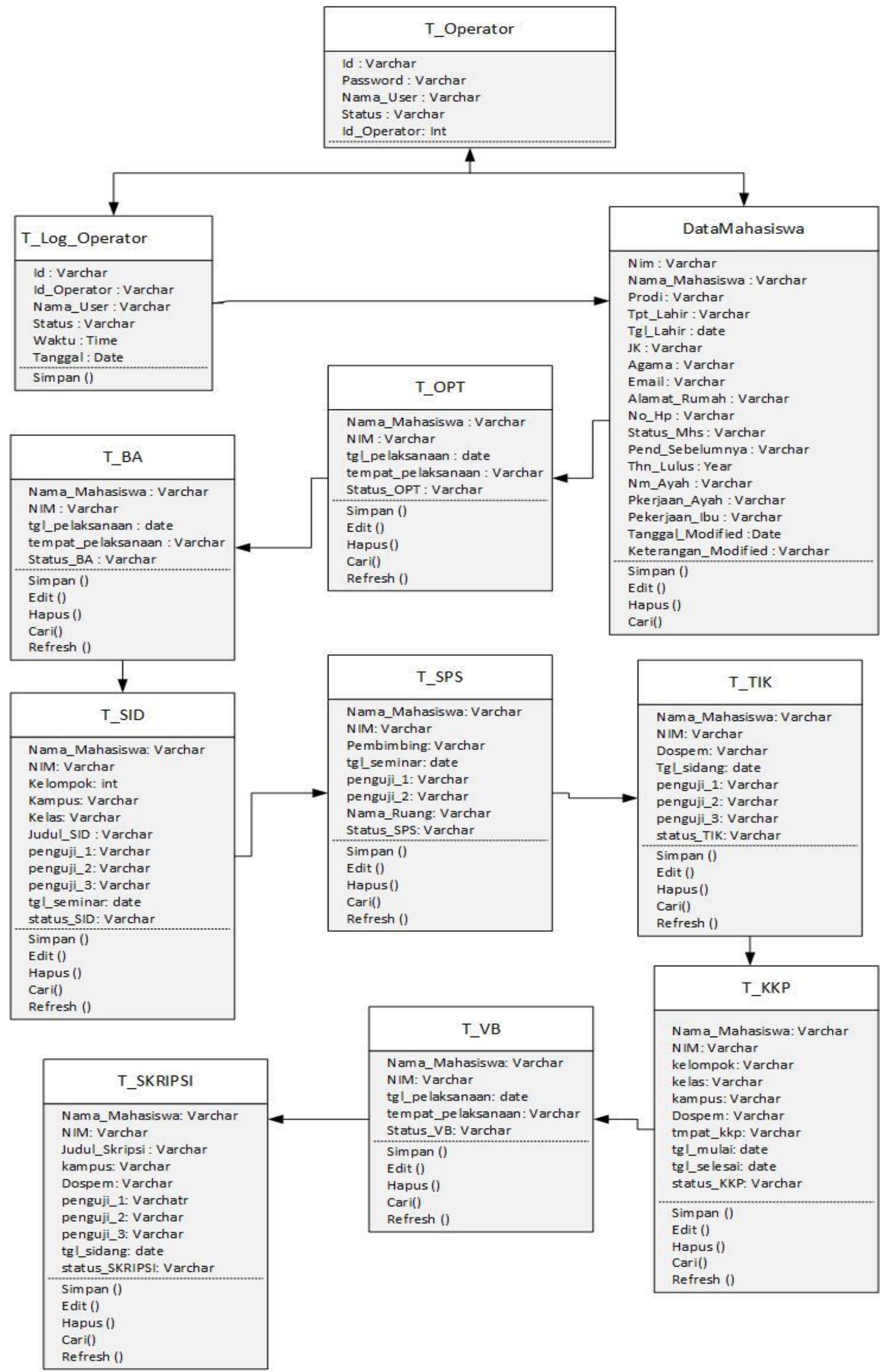

Gambar 5: Class Diagram Sistem 


\subsubsection{Tahap Desaign Database}

Database merupakan suatu kumpulan file-file yang berguna dalam hal menyimpan data-data untuk proses pengambilan keputusan. Dalam hal merancang sebuah sistem yang berbasis database, perancangan database merupakan suatu aspek yang perlu mendapat perhatian yang khusus. Maka dibuat databe kegiatan mahasiswa yang memiliki beberapa tabel yang diperlukan yaitu operator, log operator, data mahasiswa, OPT, BA, SID, SPS, TIK, VIBI, KKP, SKRIPSI, Status kegiatan.

\subsubsection{Tahap Desain Tampilan}

Pada tahap desain tampilan, peneliti menggunakan konsep wireframe untuk desain interface dimana pada bagian ini dilakukan proses seleksi dan penempatan elemen misalnya tombol, link, judul, text-align, fontsize, dll yang bertujuan sebagai media bagi pengguna dalam berinteraksi dengan tampilan.

\section{Desain Menu Login}

Tampilan awal saat pengguna mengakses sistem, adalah tampilan login yang berfungsi sebagai pintu masuk dan proses identifikasi hak akses pengguna setelah masuk kedalam sistem. Tampilan login adalah sebagai berikut

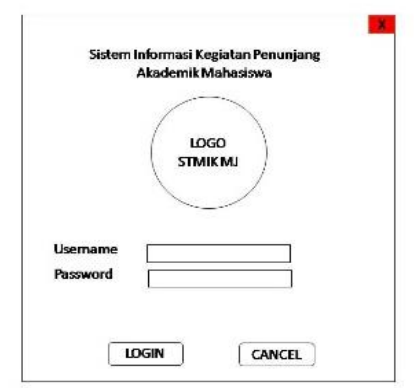

Gambar 6. Desain Menu Login

2. Desain Halaman Utama

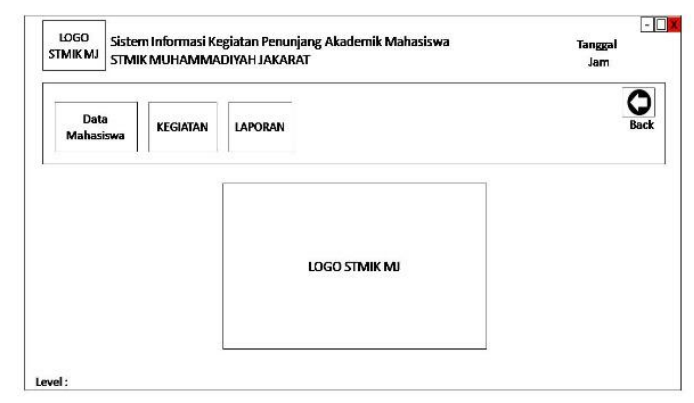

Gambar 7. Desain Halaman Utama
Halaman Utama adalah tampilan awal ketika user berhasil masuk ke sistem. Tampilan ini menampilkan beberapa pilihan menu, dibawah ini tampilan untuk manajemen halaman utama sistem

\section{Desain Tambah Data Mahasiswa}

Form tambah data mahasiswa digunakan untuk menambahkan data mahasiswa dikampus STMIK MJ. Dibawah ini tampilan form tambah data mahasiswa

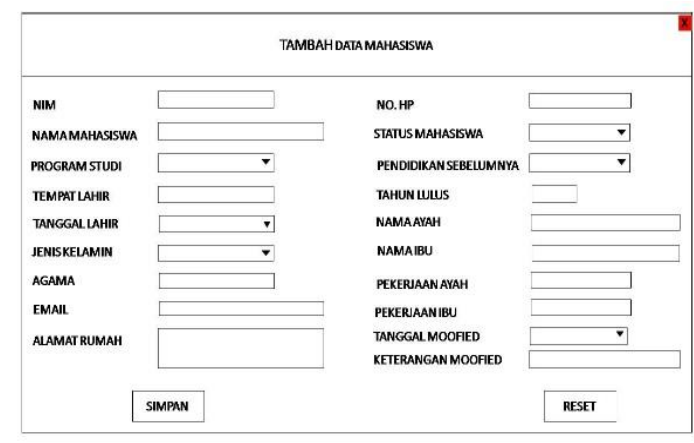

Gambar 8. Desain Tambah Data Mahasiswa

\section{Desain Tambah Data Kegiatan}

Form tambah data kegiatan digunakan untuk menambahkan data mahasiswa yang akan atau telah mengikuti kegiatan. Pada form ini di input nama mahasiswa, nim, tanggal pelaksanaan kegiatan, serta status kegiatan. Dibawah ini tampilan form tambah data kegiatan

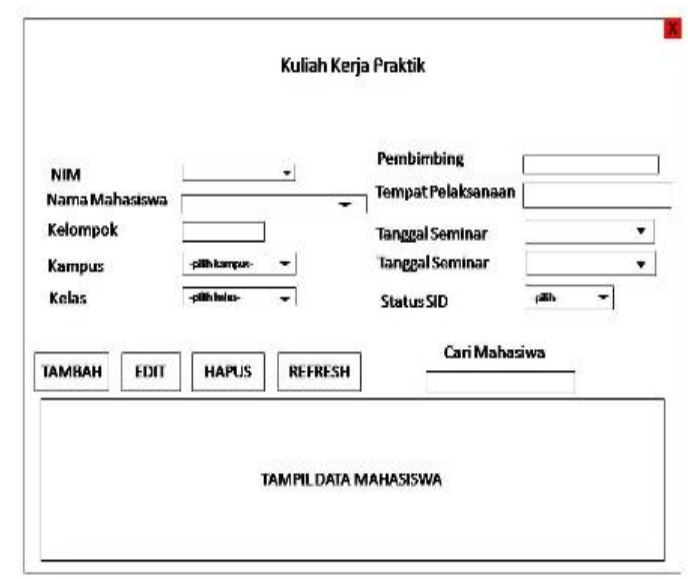

Gambar 9. Desain Form Tambah Data Kegiatan

\section{Desain Form Laporan Status Kegiatan}

Form laporan status kegiatan berisi data mahasiswa yang telah atau belum mengikuti kegiatan. Pada form laporan dapat dipilih 
sesuai periode ataupun kegiatan yang ada. Form laporan akan menampilkan nama-nama mahaisiswa serta status kegiatan mahasiswa

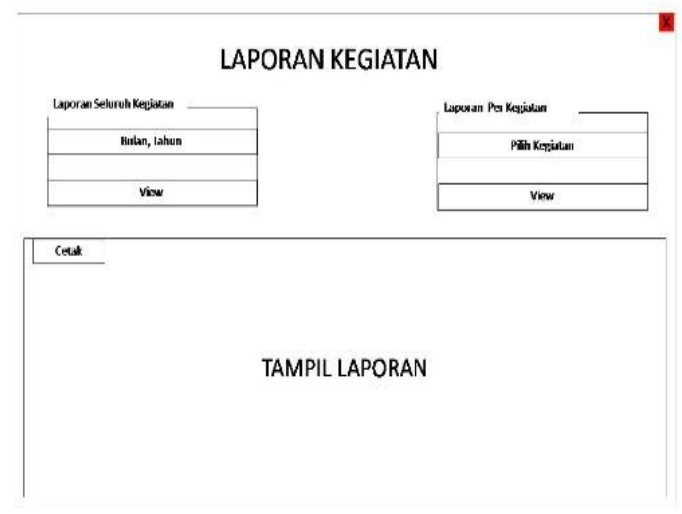

Gambar 10. Desain Form Laporan Status Kegiatan

\subsection{Tahap Coding \& Testing}

\section{Coding}

Dari hasil analisis dan desain yang telah dilakukan, peneliti menerjemahkan desain ke dalam bahasa yang di kenali komputer yaitu bahasa pemrograman yang berbentuk code ke dalam aplikasi Microsoft Visual Studio 2010. Berikut salah satu code dalam pembuatan module koneksi visual basic ke database.

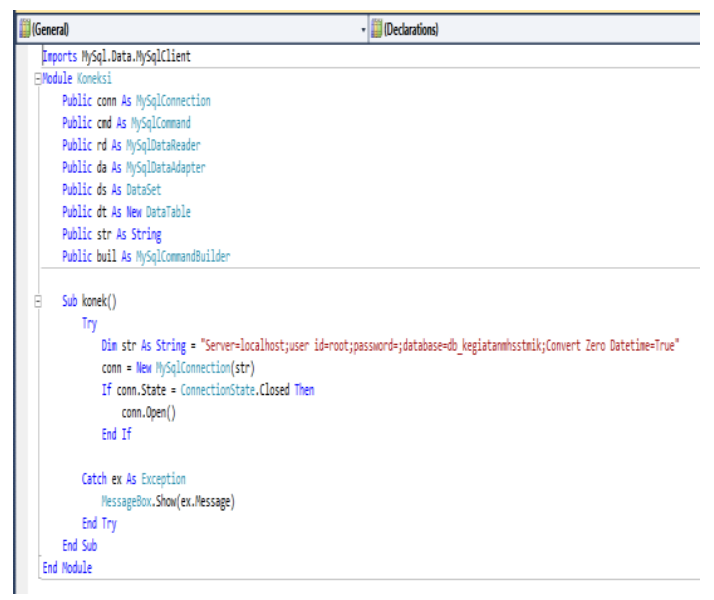

Gambar 11. Listing Code

\section{Testing}

Setelah dilakukan coding keseluruhan maka dilakukan testing untuk menguji sistem, Jika terjadi kesalahan penginputan data maka sistem akan memunculkan pesan kesalahan penginputan data. Tipe testing yang digunakan untuk menguji hasil coding yang telah dilakukan adalah Boundary Value Analysis.

\subsection{Tahap Implementasi Sistem}

Tahapan ini merupakan tahap menuju akhir dalam membangun sebuah sistem. Setelah melakukan tahapan analisa, desain, pengkodean dan testing maka sistem yang telah jadi bisa digunakan oleh user.

1. Implementasi menu login

Gambar 12 di bawah ini menunjukan tampilan halaman login hasil implementasi.

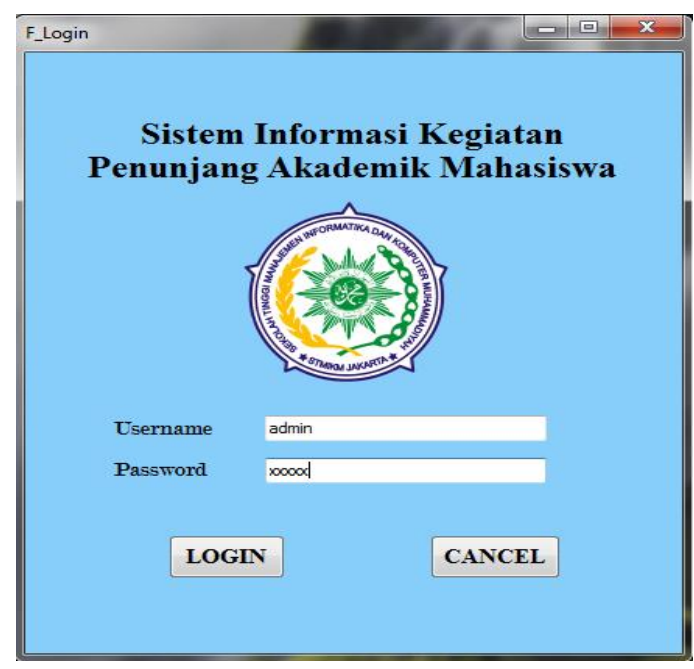

Gambar 12. Halaman Login

2. Implementasi halaman utama

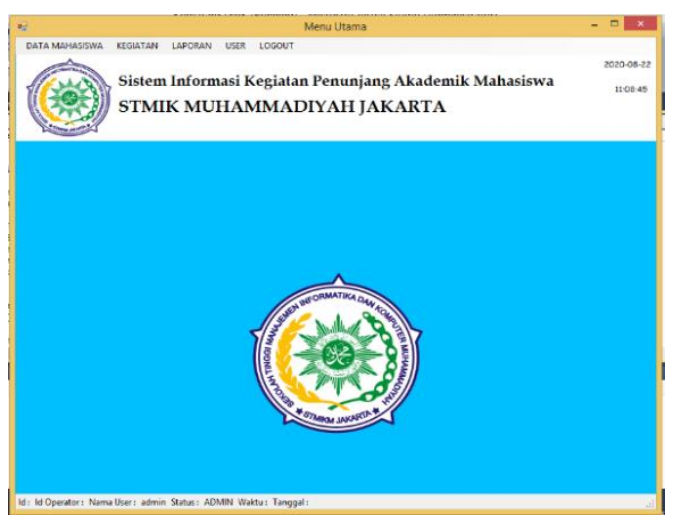

Gambar 13. Halaman Utama

3. Implementasi tambah data mahasiswa

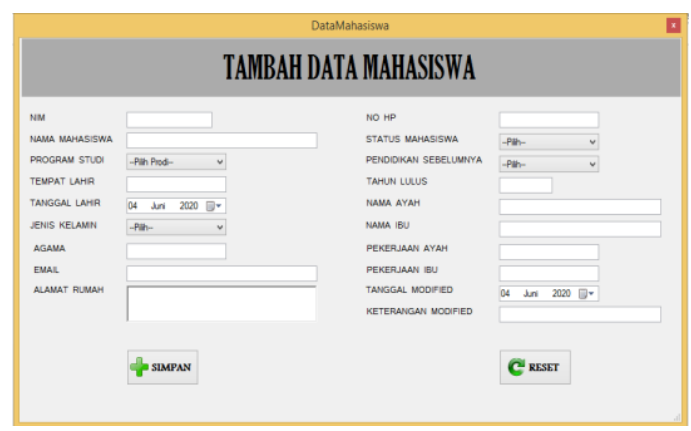

Gambar 14. Form Tambah Data Mahasiswa 
4. Implementasi tambah data kegiatan

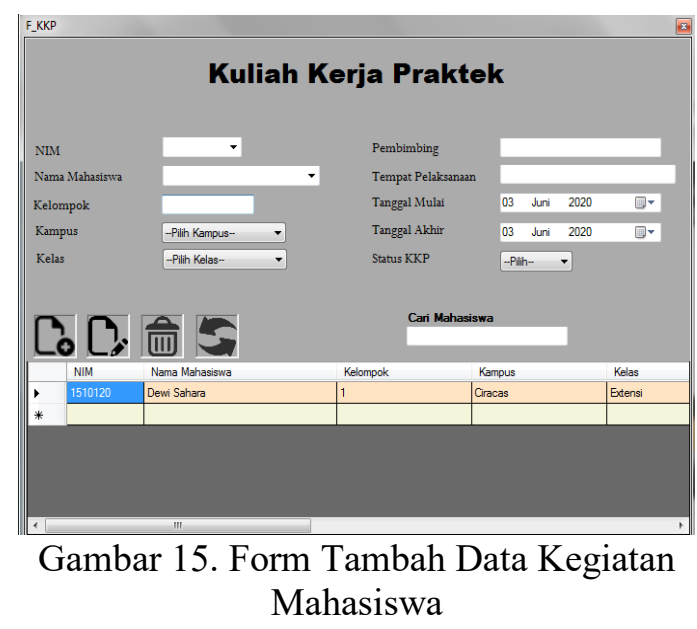

5. Implementasi laporan status kegiatan

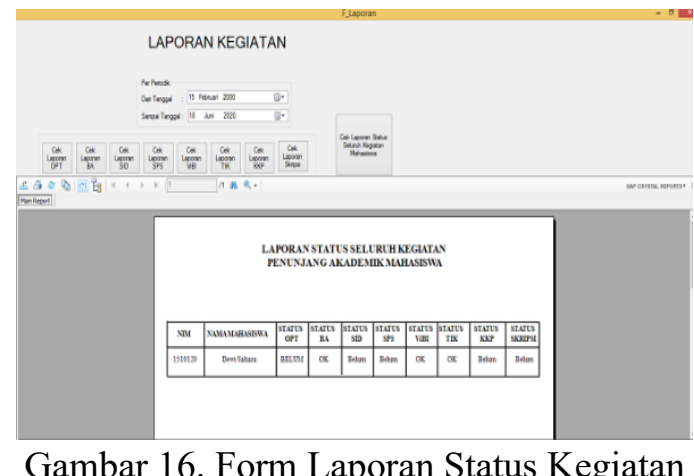

\subsection{Tahap Maintenance}

Perawatan sistem dilakukan oleh admin. Perawatan dapat dilakukan secara berkala setiap satu, tiga, enam bulan atau setahun sekali atau dapat disesuaikan dengan kebutuhan yang berjalan. Adapun perawatan yang dapat dilakukan yaitu backup data dan penambahan form atau fitur.

\section{PENUTUP}

\subsection{Kesimpulan}

Kesimpulan yang dapat di ambil dari penelitian ini adalah:

1. Sistem ini dapat dimanfaatkan sebagai media penyimpanan data kegiatan penunjang akademik mahasiswa pada Sekolah Tinggi Manajemen Informatika dan Komputer Muhammadiyah Jakarta (STMIK MJ)

2. Menu utama sistem terdapat 3 pilihan menu yaitu Data Mahasiswa, Kegiatan, Laporan. Menu Data Mahasiswa berfungsi untuk menambahkan data mahasiswa. Menu Kegiatan terdapat 8
Daftar Kegiatan Mahasiswa. Pada Menu Laporan dapat melihat dan mencetak laporan kegiatan.

3. Sistem ini terdiri dari 8 form kegiatan yaitu Form OPT, Form Baitul Arqam (BA), Form Sistem Informasi Dakwah (SID), Form Seminar Proposal Skripsi (SPS), Form Visualisasi Basic Islam (ViBI), Form Kuliah Kerja Praktek (KKP), Form Tilawah Ibadah Kitabah (TIK) dan Form Skripsi. Di dalam masing-masing form terdapat button yang berfungsi sebagai input, edit, delete, refresh, kolom cari mahasiswa dan satu kotak untuk menampilkan data mahasiswa.

4. Sistem di lengkapi dengan cetak laporan data perkegiatan dan data seluruh kegiatan

5. Admin dapat mengetahui mahasiswa yang telah dan belum mengikuti kegiatan yang dilaksanakan dengan mencari nama mahasiswa pada sistem atau dengan melihat laporan seluruh kegiatan.

6. User terdiri dari Ketua Program Studi Sistem Informasi, Ketua Program Studi Teknik Informatika, Kepala PUSAKA, Waket Bidang Kemahasiswaan dan Akademik, Kepala Bagian Akademik. User hanya bisa mengecek laporan kegiatan yang ada.

7. Dengan adanya aplikasi ini, diharapkan dapat membantu panitia pelaksana dalam penyimpanan data-data kegiatan yang telah dilaksanakan agar mudah untuk dicari ketika dibutuhkan.

\subsection{Saran}

1. Sistem ini masih dibangun dalam lingkup sederhana, belum mencakup semua data kegiatan yang ada.

2. Sistem dibangun berbasis desktop offline, diharapkan sistem dapat dikembangkan berbasis online agar dapat di akses tanpa harus menginstal aplikasi.

3. Sistem yang dibangun hanya meliputi 8 kegiatan pokok penunjang akademik mahasiswa, diharapkan sistem dapat dikembangkan untuk penginputan data mahasiswa yang mengikuti organisasi yang ada di STMIK MJ.

4. Diharapkan sistem dapat dikembangkan sehingga terdapat informasi mengenai pembayaran mahasiswa yang mengikuti kegiatan. 


\section{DAFTAR PUSTAKA}

[1] Elisabet Yunaeti dan Rita Irviani. 2017.Pengantar Sistem Informasi. CV.Andi Offset, Yogyakarta.

[2] Boonie Soeherman, Marion Pinontoan. 2008. Designing Information System.PT Elex Media Komputindo.
[3] Hutahean Japerson. 2014. Konsep Sistem Informasi. Deepublish, Yogyakarta

[4] Handayani Tri Wahyu. 2016. Kuliah Jurusan Apa? Fakultas Teknik Jurusan Arsitektur Dan Perencanaan Wilayah \& Kota.PT.Gramedia. Jakarta

[5] Jamaludin. 2019. Buku Cerdas Pemrograman C\# Berbasis Desktop Untuk Pemula. Yayasan Kita Menulis 